\title{
Vasopressin in plasma and CSF of patients with subarachnoid haemorrhage
}

\author{
H M M A THER, V A NG, A ND J S JENKINS \\ From the Department of Medicine, St George's Hospital Medical School, London
}

S U M M ARY Arginine vasopressin was measured in the bood and cerebrospinal fluid (CSF) of 42 patients with subarachnoid haemorrhage. Increased concentrations of vasopressin were present in 10 patients, of whom eight had bled from an anterior communicating artery aneurysm. In three patients high blood vasopressin values were associated with gross hyponatraemia. Five patients were found to have increased CSF vasopressin concentrations in the presence of normal plasma values and in all of these the level of consciousness was severely disturbed. It is suggested that an increased secretion of vasopressin into the blood or CSF may be a contributory factor in the worsening condition of some patients with subarachnoid haemorrhage.

Disturbances in sodium metabolism have frequently been reported in association with subarachnoid haemorrhage ${ }^{12}$ and hyponatraemia in particular has been implicated in the worsening clinical condition of some patients. A low serum sodium concentration has sometimes been attributed to the inappropriate secretion of antidiuretic hormone, vasopressin, ${ }^{2} 3$ although this diagnosis is usually made on clinical grounds only, without knowledge of the actual concentration of vasopressin in the blood, mainly because assay of the hormone is not readily available. With the recent development of sensitive radioimmunoassays it has been shown that vasopressin is also present in normal cerebrospinal fluid (CSF), ${ }^{45}$ and it has been suggested that CSF may provide a transport system whereby neurohypophyseal secretion can reach various parts of the brain. ${ }^{6}$ With these considerations in mind, we have determined the concentration of vasopressin both in plasma and CSF of patients with subarachnoid haemorrhage, and have attempted to correlate the findings with the clinical condition.

\section{Patients and methods}

Forty-two patients were studied in whom the diagnosis of subarachnoid haemorrhage had been established by

Address for reprint requests. Professor JS Jenkins, St George's Hospital Medical School, Cranmer Terrace, London SW17 ORE.

Accepted 27 December 1981 lumbar puncture. Cerebral angiography was performed in all cases and arterial abnormalities were found in 32 patients: anterior communicating artery aneurysm (14), posterior communicating artery aneurysm (12), middle cerebral artery aneurysm (2), multiple aneurysms (3), parietal angioma (1). One of the 10 patients in whom no arterial abnormality could be demonstrated had an extensive temporal lobe haematoma. After the diagnosis had been made, lumbar CSF and blood samples were taken simultaneously for measurement of arginine vasopressin by a highly specific radioimmunoassay method previously described. ${ }^{4}$ Using this method it has been established that in a series of normally hydrated subjects without brain disease plasma vasopressin ranged from 1.9$3.9 \mathrm{pmol} / 1$ (mean $\pm S D=2 \cdot 8 \pm 0.7)$ and $C S F$ concentrations ranged from $1.4-3.6 \mathrm{pmol} / 1$ (mean 2.4士0.7). Paired CSF and plasma samples were always assayed together. Plasma electrolytes and osmolality were also determined in each case. At the time of the investigation 20 patients were fully alert, 16 were drowsy, and six were comatose.

\section{Results}

The values for the plasma and CSF concentrations in all patients are shown in the figure. Thirty-two patients, including all those who were fully alert, had vasopressin values which were within the normal range for plasma and CSF. Two of these had moderately decreased plasma sodium concentrations of 129 and $128 \mathrm{meq} / 1$ respectively. In 10 patients vasopressin conrentrations were increased 


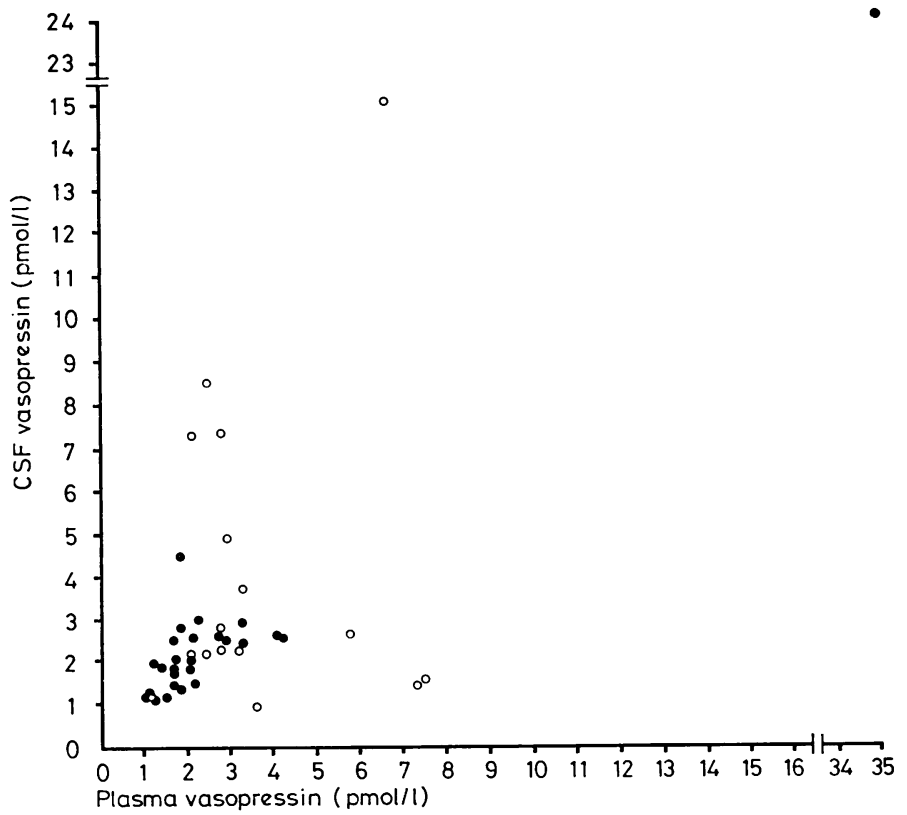

Figure Plasma and CSF concentrations of vasopressin in patients with subarachnoid haemorrhage. $\bigcirc=$ patients with anterior communicating artery aneurysms. $\bullet=$ remaining patients. either in the plasma or CSF, and sometimes in both fluids. All with increased values, apart from two patients, had anterior communicating artery aneurysms. These findings are further analysed in the table which also shows the plasma sodium, osmolality and the level of consciousness.

In patients 1-5 plasma vasopressin was increased, and in three of these (nos 1, 3, 4) plasma sodium was considerably decreased. Two patients had increased vasopressin concentrations in both plasma and CSF, and the highest value was found in a patient with a large temporal lobe haematoma. In five patients (nos 6-10) CSF vasopressin was increased in the presence of normal plasma values; a raised CSF vasopressin value persisted in two patients when they were re-examined 11 and 14 days later. All of the 10 patients with increased vasopressin concentrations had an impaired level of consciousness, and three of those with raised CSF values were comatose and subsequently died.

Table Abnormal plasma or CSF vasopressin concentrations in patients with subarachnoid haemorrhage

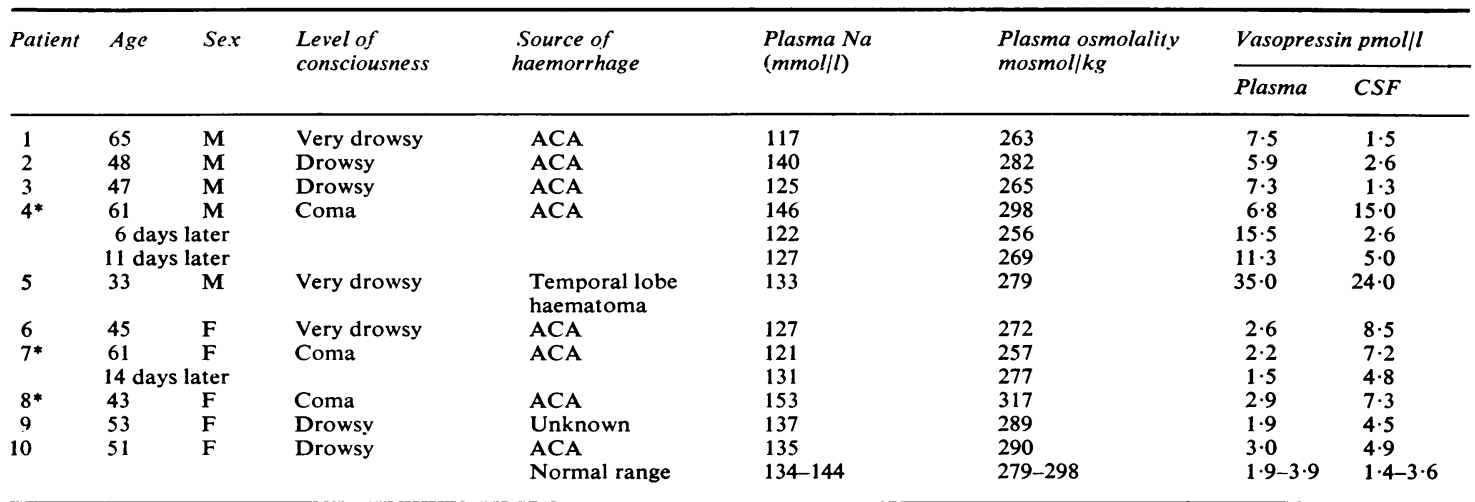

*Died; ACA = anterior communicating artery. 


\section{Discussion}

These results show that in approximately $25 \%$ of this series of patients with subarachnoid haemorrhage, increased concentrations of vasopressin were present in the plasma or CSF. Hyponatraemia was present in a total of seven patients and was of sufficient severity in five to be a contributory cause of their impaired level of consciousness. In three of these patients the high concentration of vasopressin which was found in the blood provides a direct confirmation that an inappropriate secretion of antidiuretic hormone can occur in subarachnoid haemorrhage. It is important to identify this complication since improvement can be obtained by simple restriction of the fluid intake. In the presence of a normal or low plasma osmolality the cause of the raised plasma vasopressin concentrations must be outside the normal osmotic regulation of the hormone. In experimental animals, a sudden increase in intracranial pressure, produced either by the injection of blood into the subarachnoid space or by cerebral compression, leads to a rapid rise in blood vasopressin concentrations. ${ }^{7}$ It is, however, significant that all the patients with abnormal values in the present series, apart from two, had bled from an anterior communicating artery aneurysm. In a detailed histological study of patients dying from subarachnoid haemorrhage, Crompton ${ }^{8}$ showed that haemorrhagic and ischaemic lesions in the anterior hypothalamus were particularly associated with haemorrhage from anterior communicating artery aneurysms, and it seems likely that these lesions could result in an abnormal release of vasopressin from hypothalamic neurons.

Of particular interest was the observation that CSF vasopressin concentrations were increased in some patients with normal plasma values, although in normal subjects, CSF values are usually slightly lower than those of the plasma. ${ }^{4}$ It has been shown, however, that there is a bloodCSF barrier to the hormone ${ }^{4}$ and it seems that excessive secretion of vasopressin into the CSF is independent of the classical hypothalamicneurohypophyseal release of hormone into the blood. The origin of the CSF vasopressin could be a direct secretion into the ventricles since, by the use of immunohistochemical methods, vasopressin fibres have been traced from the paraventricular nucleus of the hypothalamus to the choroid plexus and the surface of the lateral ventricle. ${ }^{1011}$ In addition, a direct passage of vasopressin from the brain into the CSF is possible since it is now known that various extra-hypothalamic areas of the brain contain the peptide. ${ }^{12} 13$ The possibility that increased concentrations of vasopressin in the CSF are of clinical importance receives support from the experiments of Raichle and Grubb, ${ }^{14}$ who infused vasopressin into the cerebral ventricles of rhesus monkeys and observed that the permeability of the brain to water was greatly increased, whereas raising the plasma concentration of the hormone had no such effect. Cerebral oedema often accompanies a worsening of the clinical condition, so that it is perhaps significant that all our patients with increased CSF vasopressin concentrations had gross impairment of consciousness, and three subsequently died.

There are many reasons, some of which are as yet unknown, for the high morbidity and mortality in subarachnoid haemorrhage; it seems likely that in some cases, especially those with anterior communicating artery aneurysms, an increased secretion of vasopressin into the blood or CSF is an important contributory factor.

We thank members of the Departments of Neurosurgery and Neurology, Atkinson Morley's Hospital for their close co-operation in obtaining samples.

This work was supported by a grant from the Wellcome Trust.

\section{References}

1 Buckell M, Richardson A, Sarner M. Biochemical changes after spontaneous subarachnoid haemorrhage. II Neurol Neurosurg Psychiatry 1966; 29: 291-8.

2 Joynt RJ, Afifi A, Harbison J. Hyponatraemia in subarachnoid haemorrhage. Arch Neurol 1965; 13:633-8.

3 Wise BL. Syndrome of inappropriate antidiuretic hormone secretion after spontaneous subarachnoid haemorrhage: a reversible cause of clinical deterioration. Neurosurgery 1978; 3:412-4.

4 Jenkins JS, Mather HM, Ang V. Vasopressin in human cerebrospinal fluid. J Clin Endocrinol Metab 1980; 50:364-7.

5 Luerssen TG, Shelton RL, Robertson GL. Evidence for separate origin of cerebrospinal fluid vasopressin. Clin Res 1977; 25:14A.

6 Rodriguez EM. The cerebrospinal fluid as a pathway in neuroendocrine integration. $J$ Endocrinol 1976; 71:407-43.

7 Rap ZM, Chwalbinska-Moneta J. Vasopressin concentration in blood during acute short-term intracranial hypertension in cats. Adv Neurol 1978; 20:381-88.

8 Crompton MR. Hypothalamic lesions following the rupture of cerebral berry aneurysms. Brain 1963; 86:301-14. 
9 Vorherr H, Bradbury MWB, Hoghoughi M, Kleeman CR. Antidiuretic hormone in cerebrospinal fluid during endogenous and exogenous changes in its blood level. Endocrinology 1968; 83:246-50.

10 Buijs RM, Swaab DF, Dogterom J, van Leeuwen FW. Intra-and extra hypothalamic vasopressin and oxytocin pathways in the rat. Cell Tissue Res $1978 ; 186: 423-33$.

11 Brownfield MS, Kozlowski GP. The hypothalamo- choroidal tract. Cell Tissue Res 1977; 178:111-27.

12 Hawthorn J, Ang V, Jenkins JS. Localization of vasopressin in the rat brain. Brain Res 1980; 197: 75-81.

13 Rossor MN, Iversen LL, Hawthorn J, Ang V, Jenkins JS. Extra-hypothalamic vasopressin in human brain. Brain Res 1981. In press.

14 Raichle ME, Grubb RL. Regulation of brain water permeability by centrally-released vasopressin. Brain Res 1978; 143:191-4. 